\title{
The Connotation of Investment Behavior Rigidity and Its Relationship with Irrational Investment Behavior
}

\author{
Gao Kai \\ Jiangsu Vocational College of Agriculture and Forestry, \\ Zhenjiang, China \\ School of Business, Nanjing Normal University, Nanjing, \\ China
}

\author{
Ji Genbao \\ Jiangsu Vocational College of Agriculture and Forestry, \\ Zhenjiang, China
}

\begin{abstract}
In order to study the mechanism of investment behavior rigidity, we examined the relationship between investment behavior rigidity and other irrational investment behavior, such as escalation of commitment and disposition effect. First, we developed an investment simulation system, manipulated five stocks' price during thirty-six periods to test investors' behavioral patterns in securities trading. Then, we investigated the relationship between investment behavior rigidity, escalation of commitment and disposition effect. The results summarized as follows: first, investors are exhibited disposition effect and escalation of commitment in securities trading; second, sex, education, duration of securities trading, and investment amount did not affect the disposition effect and escalation of commitment; and third, there is a positive correlation between investment behavior rigidity and escalation of commitment. The results of this paper support the validity of prospect theory in explaining the phenomenon of escalation of commitment and disposition effect.
\end{abstract}

Keywords-Investment behavior rigidity; Escalation of commitment; Disposition effect

\section{INTRODUCTION}

Factors such as the split shareholding and the imperfect information disclosure mechanism have led to strong Knight uncertainty in China's stock market. There are two types of investors in this decision-making situation. One type of investor can maintain the original investment direction without negative information impact, while the other type of investor is just the opposite. They are vulnerable to negative information and encounter Immediately after the short-term defeat, the investment will be withdrawn. For the first category of investors, their continuous investment in projects or assets can enable them to make up for losses and even obtain excess returns when prices reverse, but on the other hand, if the market continues to slump, prices continue to fall, holding Decisions will bring huge losses to them. For the second type of investors, they constantly adjust their investment strategies and even investment directions based on market feedback. In the short term, this kind of inertial strategy investment behavior may reduce losses, but in the long run, this kind of investment behavior often makes Investors missed many opportunities. There is a significant "rigid" feature for the maintenance and ongoing behavior of the original investment decisions.

This paper was sponsored by zhenjiang science and technology project (RK2018021).

\section{LITERATURE REVIEW AND HYPOTHESES}

\section{A. Investment behavior rigidity}

Investment behavior rigidity refers to the stability and unchangeable characteristics of the investment behavior of the individual in the investment process due to factors such as falling asset prices and negative information. Its external performance is the persistence behavior of investors in the original decision-making in the face of unfavorable information and setbacks. In an uncertain situation, the market is full of information with unknown authenticity. Investors can neither obtain complete information related to decision-making, nor can they accurately judge the authenticity of information and the results of decision-making schemes. They can only rely on limited information. Make decisions according to the logic of process rationality. Investors with stronger investment behavior will maintain their original investment portfolio more in their investment decisions, while investors with weaker investment behavior will change more frequently [1]. Investment behavior rigidity is a behavioral indicator that measures the extent to which investors maintain their investment objectives and strategies in the investment process.

\section{B. Escalation of Commitment}

A typical escalation of commitment has three characteristics: a lot of resources have been invested (such as money, time or effort); the initial action has not achieved the desired effect or is actually on the verge of failure, that is, a negative feedback has been received; investors can decide either to continue investing in an attempt to recover the costs already paid or to withdraw completely from the operation[4]. Escalation of commitment means that investors continued to devote resources to purchasing more while they suffered a serious setback in their previous investments in order to share the loss of their previous investments. Prospect theory and self-defense theory explain the causes of escalation of commitment from the perspective of cognitive process and motivation. Both theories declared that escalation of commitment is a distortion of investors' cognition and is mainly emotional and irrational. However, the decision dilemmas theory argued that escalation of commitment is not totally irrational. Bowen pointed that negative feedback and social value norms are not the main reasons for the escalation of commitment. The ambiguity of feedback and the lack of objective criteria for evaluating feedback are the major contributors to escalation of commitment. The experimental 
methods can not only overcome the deficiencies of indirect data, but also investigate the process of personal information processing through a programmed experimental platform .

\section{Disposition Effect}

The most widely accepted interpretation of the disposition effect is the prospect theory, which argues that due to the existence of the framework effect, when the stocks held are profitable, the effect of the investor continuing to hold the profitable stock is less than the utility of selling the profitable stock. When the stock held is losing money, the effect of the investor continuing to hold the losing stock is greater than the utility of selling the losing stock. Weber controls the price of the six risk assets and verifies the existence of disposition effect in the student-oriented investment trial. It has also been found that when risk assets are automatically sold in each period of the transaction, disposition effect is greatly reduced. Zhao Xuejun first verified disposition effect of Chinese investors by analyzing nearly 10,000 investor accounts of a large sales department. Sun Jianjun and others found that investors with investment experience and no actual investment experience showed obvious disposition effects through group experiments. Different investors show a different degree of disposition effect. Elzbieta builds a model from both the value function and the probability weight function. After numerical simulation, it is concluded that the reverse strategy trader has a stronger tendency to deal with it. Based on the Estonian stock market data, Tonn used Cox's method to measure disposition effect and found that compared with domestic investors, foreign investors often showed a reverse disposition effect and more inertial trading. In addition, experienced investors show a lower level of disposal. Zhou Mingshan et al. used the survival model to study disposition effect of fund investors, and found that male investors and fund managers with rich experience showed relatively low disposition effects[5-6].

To test the relationship between investment behavior rigidity, escalation of commitment and disposition effect, we derive hypotheses as follow:

Hypothesis 1: The stronger the investment behavior rigidity, the more significant the investor's escalation of commitment.

Hypothesis 2: The stronger the investment behavior rigidity, the more significant the investor's disposition effect.

\section{METHOD}

\section{A. Subjects}

A total of 123 subjects were randomly selected from the two groups. Group I consist of 72 undergraduates from Nanjing Normal University. These students had studied investment-related knowledge. Group II consist of 51 investors with investment experience from the Bank of Nanjing and Tianfeng Securities Ltd.

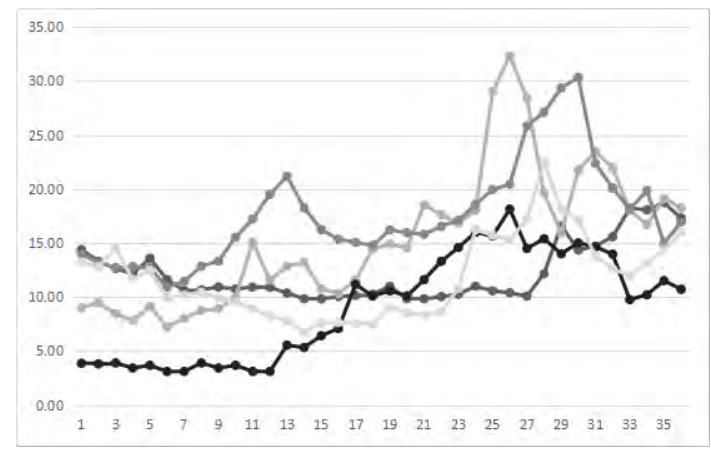

Fig. 1 Time series of stock prices used in the experiment

\section{B. Experimental Design}

The experiment was complemented by the investment simulation software. Each participant abided by the presumed 100,000 Yuan budget constraint before the experiment started, and formed a portfolio investment by buying and selling stocks. All of the subjects was informed that at the end of the experiment, the corresponding reward of $1 \%$ would be given according to the sum of the cash on the account and the market value of the stock portfolio. In addition, the subjects were informed that their stock trading activities did not affect the market price. For the participants, they faced a perfectly competitive market, which was also consistent with the real market.

We selected five stocks actually issued in the stock market of Shanghai Stock Exchange as the research objects. The five stocks came from banks, high-tech, real estate, home appliances and clothing segments, and intercepted from January 2013 to the end of December 2015 every month on the 30th Closing price as the experimental data point. In the experiment, we give the trend of the first four periods of each stock, after the completion of the participants to buy and sell operation we show the price of the next period.

\section{Experimental Procedure}

The measurement of the rigidity of the investment behavior is first carried out and guided by the experimenter[1]. Second, conduct stock investment experiments. The experiment was completed in two stages. In the first stage, for the group I, the test procedure was as follows: (1) The participants were concentrated in a laboratory, and each person was given a stock "learning material" prepared in advance. The 10 major knowledge points that help the participants understand stock trading are quoted from stock books and large stock exchanges on the common sense of stock trading. (2) The experimenter reads out the instructions for the experiment, including the guidance, operation introduction and reward method. (3) The participants conducted a 32-stage investment experiment by logging into the investment simulation system through the local area network. (4) At the end of the experiment, each participant leaves the laboratory, and the experimenter leads to the next room to receive the reward corresponding to the investment performance. In the second stage, for the group II subjects, the test procedure was: (1) The participants landed on the experimental system, reading stock learning materials and experimental instructions. (2) The participants completed the experiment in the investment simulation system. (3) According 
to the social account left by the participant, the corresponding reward is issued. In the second stage, because the participants were difficult to concentrate in the same place, the experimenter configured the complete experimental system on the public network, and the participants clicked on the link to complete the experiment.

\section{Measurement}

There are three ways to measure disposition effect: the first one is developed by Shefrin and Statman. The second one is the method of survival model used in actuarial science by Feng and Seasholes; the third one is the method of "sell ratio" statistic by Odean. On the basis of Odean, Weber constructed the degree of disposition effect index, which was widely used in experimental research. We measured disposition Effect with Weber's method. Taking the bidding price as a reference point, the number of shares an investor sold the profitable stocks is $S_{i+}$, the number of shares an investor sold the losing stocks is $S_{i-}$. Then the degree of disposition effect is:

$$
\alpha_{i}=\left(S_{i+}-S_{i-}\right) /\left(S_{i+}+S_{i-}\right)
$$

Obviously, $\alpha_{i} \in[-1,1]$

For the measure of escalation of commitment, Lin proposed a calculation indicator of "P /L ratio". However, this method adds investors' influence on the buying of profitable stocks so it is not accurate. According to the connotation of escalation of commitment, we developed an indicator to measure the degree of escalation of commitment. Taking the bidding price as a reference point, the number of shares an investor bought the profitable stocks is $B_{i+}$, the number of shares an investor bought the losing stocks is $B_{i-}$. Then the degree of escalation of commitment is:

$$
\beta_{i}=B_{i-} /\left(B_{i-}+B_{i+}\right)
$$

Obviously, $\beta_{i} \in(0,1)$.

\section{RESULT}

Due to the difference in psychological valence, when we analyze the relationship between investment behavior rigidity and Escalation of Commitment and disposition effects, we will test the student group and the actual investment component, so as to ensure the accuracy of the investment behavior rigid experiment. Ensure the reliability of the analysis results.

In the student group, we respectively use the Escalation of Commitment index and the treatment effect index as the dependent variables, gender, age, and family income as control variables, and the investment behavior rigidity as the independent variable for hierarchical regression analysis. The results of the analysis showed that gender, age, and household income status did not significantly affect the commitment to continue to expand, and did not significantly affect the treatment effect indicators. This is inconsistent with the research results of Sun Jianjun and others. We think there may be two reasons for this. First, in this trial, the average age of the student group was 20.15 years old, and the age difference between individuals was not significant. Second, escalation of commitment and disposition effect reflects the decision-making habits of investors in the sequence of investment. The formation of this habit must be the result of long-term accumulation, and it varies from person to person, and its intrinsic essence is an intuitive preference. Therefore, the factors affecting the individual's commitment to the expansion and disposition effect are not only the external representation information, but the deep psychological and behavioral characteristics. The analysis results show that in the student group, the rigidity of investment behavior has a significant impact on escalation of commitment, with a significance level of 0.05 .

TABLE I REGRESSION MODEL TEST OF ESCALATION OF COMMITMENT (STUDENTS)

\begin{tabular}{l|l|l|l|l}
\hline & \multicolumn{3}{|c}{ Escalation of commitment } \\
\hline & \multicolumn{2}{|c}{ Model I } & \multicolumn{2}{c}{ Model II } \\
\hline & $\beta$ & $\mathrm{t}$ & $\beta$ & $\mathrm{t}$ \\
\hline constant & 0.524 & 0.971 & 0.449 & 0.855 \\
\hline sex & 0.108 & 1.162 & 0.086 & 0.948 \\
\hline age & -0.013 & -0.522 & -0.016 & -0.679 \\
\hline hinc & -0.031 & -1.065 & -0.035 & -1.223 \\
\hline ibr & & & $0.036^{*}$ & 2.216 \\
\hline R2 & 0.046 & & 0.112 & \\
\hline Adj.R2 & 0.004 & & 0.058 & \\
\hline
\end{tabular}

TABLE II REGRESSION MODEL TEST OF DISPOSITION EFFECT(STUDENTS)

\begin{tabular}{l|l|l|l|l}
\hline & \multicolumn{4}{c}{ disposition effect } \\
\hline & \multicolumn{2}{|c}{ Model I } & \multicolumn{2}{c}{ Model II } \\
\hline & $\beta$ & $\mathrm{t}$ & $\beta$ & $\mathrm{t}$ \\
\hline constant & 0.814 & 1.826 & 0.824 & 1.831 \\
\hline sex & 0.017 & 0.217 & 0.019 & 0.249 \\
\hline age & -0.014 & -0.688 & -0.014 & -0.661 \\
\hline hinc & 0.017 & 0.693 & 0.017 & 0.706 \\
\hline ibr & & & -0.005 & -0.322 \\
\hline R2 & 0.014 & & 0.015 & \\
\hline Adj.R2 & 0.01 & & 0.04 & \\
\hline
\end{tabular}

TABLE III REGRESSION MODEL TEST OF ESCALATION OF COMMITMENT (EXPERIENCED)

\begin{tabular}{l|l|l|l|l}
\hline & \multicolumn{3}{|c}{ Escalation of commitment } \\
\hline & \multicolumn{2}{|c}{ Model I } & \multicolumn{2}{c}{ Model II } \\
\hline & $\beta$ & $\mathrm{t}$ & $\beta$ & $\mathrm{t}$ \\
\hline constant & 1.044 & 3.943 & 0.766 & 2.820 \\
\hline sex & -0.022 & -0.299 & -0.004 & -0.059 \\
\hline age & -0.006 & -0.920 & -0.005 & -0.846 \\
\hline hinc & -0.023 & -0.974 & -0.015 & -0.672 \\
\hline education & -0.081 & -2.307 & -0.059 & -1.732 \\
\hline Amount & $0.077^{*}$ & 2.995 & $0.063^{*}$ & 2.551 \\
\hline time & $-0.068^{*}$ & -2.586 & $-0.069^{* *}$ & -2.807 \\
\hline ibr & & & $0.034^{*}$ & 2.576 \\
\hline R2 & 0.292 & & 0.387 & \\
\hline Adj.R2 & 0.195 & & 0.287 & \\
\hline
\end{tabular}


In the actual investor group, we respectively pledged the renewal index and disposition effect index as the dependent variables, gender, age, household income status, education level, time of market entry and the amount of funds invested in the stock market as control variables, and investment behavior rigidity as self-determination The variables were subjected to regression analysis. The analysis results show that the time of entering the market and the amount of funds invested in the stock market and the commitment to continue to expand have significant effects. Among them, the amount of funds invested in the stock market and the promised continuation index are significant at the 0.05 level, the direction is positive; the entry time and Escalation of Commitment index is at 0.01 . Significantly related horizontally, the direction is negative. The investment behavior rigidity and Escalation of Commitment index are significant at the 0.05 level, and the direction is positive. Comparing the analysis results, it can be seen that the stronger the investment behavior is, the stronger the commitment is to continue to expand, and the assumption $2 \mathrm{a}$ is verified.

TABLE IV REGRESSION MODEL TEST OF DISPOSITION EFFECT(EXPERIENCED)

\begin{tabular}{l|l|l|l|l}
\hline & \multicolumn{4}{c}{ disposition effect } \\
\hline & \multicolumn{2}{|c}{ Model I } & \multicolumn{2}{c}{ Model II } \\
\hline & $\beta$ & $\mathrm{t}$ & $\beta$ & $\mathrm{t}$ \\
\hline constant & 1.634 & 4.165 & 1.549 & 3.593 \\
\hline sex & -0.053 & -0.474 & -0.047 & -0.418 \\
\hline age & -0.026 & -2.602 & -0.026 & -2.551 \\
\hline hinc & -0.043 & -1.213 & -0.040 & -1.123 \\
\hline education & -0.076 & -1.460 & -0.069 & -1.279 \\
\hline Amount & $0.084 *$ & 2.220 & $0.080^{*}$ & 2.042 \\
\hline time & $-0.108^{* *}$ & -2.771 & $-0.108^{* *}$ & -2.759 \\
\hline ibr & & & 0.010 & 0.495 \\
\hline R2 & 0.276 & & 0.280 & \\
\hline Adj.R2 & 0.177 & & 0.163 & \\
\hline The analysis & $10541 \mathrm{~s}$ & & \\
\hline
\end{tabular}

The analysis results show that the time of entering the market and the amount of funds invested in the stock market and disposition effect have significant effects. Among them, the amount of funds invested in the stock market and the promised continuation index are significant at the 0.05 level, and the direction is positive; the time of entry and the promised continuation index are at 0.01 level. Significantly related, the direction is negative, which is consistent with previous research results, indicating that the longer the investor enters the market, the richer the investment experience, the lower the possibility of a disposition effect. There is no significant correlation between investment behavior rigidity and disposition effect in the table, and hypothesis 4 is not verified.

\section{CONCLUSION}

Through the method of investment experiment, this paper studies disposition effect and escalation of commitment in the securities trading, and draws the following conclusions. First, in the securities trading, investors not only have a disposition effect, but also have a commitment to continue to expand. Second, there is a positive correlation between investment behavior rigidity and Escalation of Commitment. The results of this paper further support the validity of prospect theory in explaining escalation of commitment behavior.

\section{REFERENCES}

[1] Gao Kai, The Internal Mechanism and Application Research of Investment Behavior Rigidity Under Knightian Uncertainty[D].Nanjing Normal University, nanjing, 2018. (In Chinese)

[2] LIN Y E. Throwing Good Money After Bad? The Impact of the Escalation of Commitment of Mutual Fund Managers on Fund Performance. The Journal of Behavioral Finance, 2014(15):1-15.

[3] BARBERIS N, XIONG W. What Drives the Disposition Effect? An Analysis of A Long Standing Preference Based Explanation. Journal of Finance, 2009(2):751-784

[4] ELZBIETA,KUBINSKA. Disposition Effect Among Contrarian[J]. The Journal of Behavioral Finance,2012(13):214-225.

[5] TONN T. Reverse Disposition Effect of Foreign Investors[J].The Journal of Behavioral Finance,2011(12):183-200.

[6] Kahneman D.,Thaler RH. Anomalies: Utility Maximization and Experienced Utility.[J]. The Journal of Economic Perspectives,2006(20):221-234.

[7] Thaler R. Behavioral Economics: Past, Present, and Future.[J]. American Economic Review,2016(106):1577-1600.

[8] Ferguson E.,Heckman JJ.,Corr P. Personality and economics: Overview and proposed framework.[J]. Personality and Individual Differences,2011(51):201-209.

[9] Brown S.,Taylor K. Household Finances and the Big Five Personality Traits[J]. Journal of Economic Psychology,2014(45):197-212. 